\title{
Rapid Catalytic Reduction of 4-Nitrophenol and Clock Reaction of Methylene Blue using Copper Nanowires
}

\author{
Aina Shasha Hashimi ${ }^{1}$, Muhammad Amirul Nazhif Mohd Nohan ${ }^{1}$, Siew Xian Chin ${ }^{2, *}$, \\ Sarani Zakaria ${ }^{1}$ and Chin Hua Chia ${ }^{1, *}$ \\ 1 Materials Science Program, Faculty of Science and Technology, Universiti Kebangsaan Malaysia, \\ 43600 Bangi, Selangor, Malaysia \\ 2 ASASIpintar Program, Pusat GENIUS@Pintar Negara, Universiti Kebangsaan Malaysia, \\ 43600 Bangi, Selangor, Malaysia \\ * Correspondence: chinsiewxian@ukm.edu.my (S.X.C.); chia@ukm.edu.my (C.H.C.); \\ Tel.: (+603)-8921-7552 (S.X.C.); (+603)-8921-5473 (C.H.C.)
}

Received: 10 June 2019; Accepted: 25 June 2019; Published: 28 June 2019

\begin{abstract}
Copper nanowires (CuNWs) with a high aspect ratio of $\sim 2600$ have been successfully synthesized by using a facile hydrothermal method. The reductions of 4-nitrophenol (4-NP) to 4-aminophenol (4-AP) and methylene blue (MB) to leucomethylene blue (LMB) by using sodium borohydride $\left(\mathrm{NaBH}_{4}\right)$ were used as models to test the catalytic activity of CuNWs. We showed that by increasing the CuNWs content, the rate of reduction increased as well. The CuNWs showed an excellent catalytic performance where $99 \%$ reduction of 4-NP to 4-AP occurred in just 60 s by using only $0.1 \mathrm{pg}$ of CuNWs after treatment with glacial acetic acid (GAA). The rate constant $\left(\mathrm{k}_{\mathrm{app}}\right)$ and activity factor $(\mathrm{K})$ of this study is 18 and $\sim 10^{10}$ fold in comparison to previous study done with no GAA treatment applied, respectively. The CuNWs showed an outstanding catalytic activity for at least ten consecutive reusability tests with a consistent result in 4-NP reduction. In clock reaction of $\mathrm{MB}$, approximately $99 \%$ of reduction of MB into LMB was achieved in $\sim 5$ s by using $2 \mu \mathrm{g}$ CuNWs. Moreover, the addition of $\mathrm{NaOH}$ can improve the rate and degree of recolorization of $\mathrm{LMB}$ to $\mathrm{MB}$.
\end{abstract}

Keywords: catalytic activity; clock cycle; acetic acid treatment; metal nanowires; $p$-nitrophenol; reduction of nitro compounds

\section{Introduction}

Metal nanocrystals have attracted the attention of many researchers for the applications such as catalysts, sensors, antibacterial, and flexible and transparent electrodes [1-8]. Metal based nanoparticles have unique properties such as high numbers of vacant sites and high surface area which is why they are widely used for the removal of variety of toxic substances [9]. There are several parameters that can affect the catalytic activity of metal nanocrystal such as shape, size, and degree of dispersion. Metal particles at nanoscale often have significant catalytic properties compared to their bulk counterparts thanks to their increased surface-to-volume ratio [10]. One-dimensional (1D) nanocopper has received great attention due to its high abundance and low cost [11].

A recent trend in nanocrystals applications is using them as nanocatalysts to treat toxic substances such as nitroaromatic compounds. 4-nitrophenol (4-NP) is an example of toxic substance that exists in industrial and agricultural wastewaters, and has been classified as a priority toxic pollutant by the U.S. Environmental Protection Agency (EPA). [12] There are many methods which have been employed to reduce 4-NP such as photocatalytic [13], chemical oxidation [14], and the Fenton oxidation reaction [15]. Due to its simplicity, one of the most popular methods is by $\mathrm{NaBH}_{4}$ to reduce $4-\mathrm{NP}$ to $4-\mathrm{AP}$. The reduction of $4-\mathrm{NP}\left(\mathrm{E}^{0}(4-\mathrm{NP} / 4-\mathrm{AP})=-0.76 \mathrm{~V}\right)$ by $\mathrm{NaBH}_{4}\left(\mathrm{E}^{0}\left(\mathrm{H3BO} 3 / \mathrm{BH}^{-}\right)=-1.33 \mathrm{~V}\right)$ is 
thermodynamically favorable but there is a high kinetic barrier between the mutually repelling negative ions 4-NP and $\mathrm{BH}_{4}{ }^{-}$in the absence of an effective catalyst [16]. The reduction of 4-NP by $\mathrm{NaBH}_{4}$ has become a widely used model reaction to assess catalytic properties of nanostructure materials.

Metals such as Au [3], Ag [13], Cu [17], and Pt [14] have been used in different shapes and sizes to reduce 4-NP. There are also studies that uses semiconductor catalysts such as $\mathrm{ZnO}$ [18] and $\mathrm{CuO} / \mathrm{TiO}_{2}$ [19] to reduce 4-NP. There have been several studies of using $\mathrm{Cu}$ nanocrystal and bimetallic $\mathrm{Cu}$ nanostructures [20,21] as catalysts for the reduction of 4-NP. For example, Deka et al. successfully synthesized $\mathrm{Cu}$ nanoparticles (CuNPs) that can reduce 4-NP to 4-AP in $50 \mathrm{~min}$ [17]. Zhang et al. synthesized copper nanocrystals with different diameters and tested their catalytic performance in reduction of 4-NP [22]. They concluded that $\mathrm{Cu}$ nanocubes exhibit higher catalytic activity than $\mathrm{Cu}$ polyhedrons, illustrating that different morphologies of nanostructures may perform differently from one another.

Oscillation between one or more components that occur in periodic motion is a complex reaction is called a chemical clock or oscillating reaction $[23,24]$. A clock reaction is usually based on a redox system and provides a visually reversible color change. The mechanism and features of a clock reaction may differ with different varieties of substrate. Some common examples of such reactions include the chlorate-iodine clock reaction [25], the molybdenum blue clock reaction [26], and the methylene blue (MB) clock reaction [27]. $\mathrm{MB}$ (tetramethylthionine chloride, $\mathrm{C}_{16} \mathrm{H}_{18} \mathrm{ClN}_{3} \mathrm{~S}$ ) is a blue colored thiazine dye that is water soluble. $\mathrm{MB}$ is blue when it is in an oxidizing environment and colorless as leucomethylene blue (LMB) when exposed to a reducing agent [28]. These redox properties of MB has several uses: As an analytical indicator [29], in rewritable paper [30], and as an oxygen indicator to ensure quality control in food industries [31,32]. This reaction also used to observe the catalytic performance of nanomaterials [33,34].

Clock cycles of MB has been demonstrated with several different types of catalysts and methods. Jiang et al. showed that ultrathin $\mathrm{Cu}_{7} \mathrm{~S}_{4}$ nanosheets effected the clock cycle reaction of $\mathrm{MB}$ with hydrazine [33]. Clock reaction of $\mathrm{MB}$ was also studied by Pal et al. by using $\mathrm{Au}-\mathrm{CuO}$ composite as a catalyst and ascorbic acid as a reducing agent [34]. They showed that the reduction of MB can be altered by using different amounts of catalyst. When more catalyst is added, the rate of decolorization becomes faster, following the pseudo-first order kinetics. The colorless solution of LMB can regain its blue color by gentle shaking. This is due to the aerobic oxidation of LMB to MB.

However, there are several obstacles to supported metal catalysis such as agglomeration of nanocatalysts during catalyst recovery, and reduction of specific area after being embedded on the support. Furthermore, regeneration of metals and leaching of catalyst during catalyst recovery are also matters to take concern in [35]. In this paper, we synthesized CuNWs by a simple hydrothermal route and studied its catalytic performance in the reduction of 4-NP to 4-AP and clock reaction of MB to LMB. In addition, a facile treatment using GAA was conducted on CuNWs immobilized onto cotton cloth to improve the reusability and recoverability of the CuNWs in the catalytic reduction of 4-NP.

\section{Materials and Methods}

\subsection{Materials}

Copper chloride dihydrate $\left(\mathrm{CuCl}_{2} \cdot 2 \mathrm{H}_{2} \mathrm{O}, \geq 99.0 \%\right)$, octadecylamine (ODA, $\mathrm{C}_{18} \mathrm{H}_{39} \mathrm{~N}, \geq 85.0 \%$ ), sodium borohydride $\left(\mathrm{NaBH}_{4}, \geq 98 \%\right)$, and chloroform $\left(\mathrm{CHCl}_{3}, \geq 99.8 \%\right)$ were obtained from Merck, Massachusetts, USA. Glucose $\left(\mathrm{C}_{6} \mathrm{H}_{12} \mathrm{O}_{6}, \geq 99.5 \%\right)$, methylene blue (MB, $\left.\mathrm{C}_{16} \mathrm{H}_{18} \mathrm{ClN}_{3} \mathrm{~S}, \geq 95 \%\right)$, and ascorbic acid (AA, $\mathrm{C}_{6} \mathrm{H}_{8} \mathrm{O}_{6}, \geq 99 \%$ ) were obtained from Sigma, St. Louis, MO, USA. Glacial acetic acid (GAA, $\mathrm{CH}_{3} \mathrm{COOH}, 99.85 \%$ ) was obtained from HmbG Chemicals, Hamburg, Germany. 4-Nitrophenol (4-NP, $\mathrm{C}_{6} \mathrm{H}_{5} \mathrm{NO}_{3}, 99 \%$ ) was obtained from Acros Organics, Geel, Belgium. Sodium hydroxide $(\mathrm{NaOH}$, 99\%) was obtained from SYSTERM, Essex, UK. All cotton cloths (CC, 95\% cotton) were cut to $0.5 \times 1 \mathrm{~cm}^{2}$ for each reaction. All chemicals were used as received. All solutions were prepared with deionized water. 


\subsection{Synthesis of CuNWs}

CuNWs were synthesized using a previous reported method with slight modifications [2]. Firstly, $5.6 \mathrm{mM}$ of $\mathrm{CuCl}_{2} \cdot 2 \mathrm{H}_{2} \mathrm{O}, 26.3 \mathrm{mM}$ of ODA and $2.8 \mathrm{mM}$ of AA were dissolved in $30 \mathrm{~mL}$ deionized water and sonicated for $15 \mathrm{~min}$. After that, the obtained mixture was transferred into a Teflon-lined autoclave and sealed for $20 \mathrm{~h}$ at $120^{\circ} \mathrm{C}$. After the synthesis was done, the reddish brown solution was washed with chloroform using the method outlined by Qian et al [36]. The fluffy reddish product that formed after the washing was stored in chloroform at $4{ }^{\circ} \mathrm{C}$.

\subsection{Preparations of $\mathrm{CuNWs}$ Strips}

Different amounts of CuNWs (0.1, 0.5 and $1 \mathrm{pg})$ were drop casted on a piece of CC. Each strip was treated with $10 \%$ GAA (GAA: isopropyl alcohol = 1:9) for $10 \mathrm{~min}$ by dip coating.

\subsection{Catalytic Reduction of 4-NP and Clock Reaction of MB Using CuNWs Strips}

A $5 \mathrm{~mL}$ aqueous solution containing $1 \mathrm{mM}$ 4-NP was prepared. $0.5 \mathrm{~mL}$ of $50 \mathrm{mM} \mathrm{NaBH}_{4}$ was added into the solution. CC containing CuNWs was added to this solution and stirred at $200 \mathrm{rpm}$ using magnetic stirrer. To monitor the reduction of 4-NP, the absorbance values at $400 \mathrm{~nm}$ for $4-\mathrm{NP}$ were recorded using a UV-vis spectrometer (Jenway, 7315). The reduction reactions of 4-NP were done to observe the effect of catalyst content, initial concentration of $\mathrm{NaBH}_{4}$, and initial concentration of 4-NP. The experimental conditions for the clock reaction of MB were the same as catalytic reduction of 4-NP with a slight difference in the mass of catalyst used. For clock reaction, only $2 \mu \mathrm{g}$ of CuNWs was tested. To monitor the reduction of $\mathrm{MB}$, the absorbance values at $665 \mathrm{~nm}$ for $\mathrm{MB}$ were recorded using a UV-Vis spectrometer.

The catalytic reduction efficiency of 4-NP of the as-synthesized sample was calculated as follows:

$$
\begin{aligned}
& \text { Reduction or conversion }(\%)=\frac{\mathrm{C}_{0}-\mathrm{C}_{\mathrm{t}}}{\mathrm{C}_{0}} \times 100 \% \\
& \qquad \ln [\mathrm{C}] /\left[\mathrm{C}_{0}\right]=-\mathrm{k}_{\mathrm{app}} \mathrm{t}
\end{aligned}
$$

where $\mathrm{C}$ and $\mathrm{C}_{0}$ are the concentration of $4-\mathrm{NP}$ at time $\mathrm{t}$ and 0 , respectively. The reaction rate constant $\left(\mathrm{k}_{\mathrm{app}}\right)$ was determined from the linear plot of $\ln \left(\mathrm{C} / \mathrm{C}_{0}\right)$.

\subsection{Retreatment of CuNWs Using GAA}

After each cycle, CuNWs strip was dipped into 10\% GAA for $10 \mathrm{~min}$. The reactions continued under the same parameters.

\subsection{Characterizations}

The morphologies of CuNWs were analyzed by a scanning electron microscope (FESEM, MERLIN ZEISS, Oberkochen, Germany) and transmission electron microscopy (TEM, Talos 120C Thermo Fisher, Waltham, MA, USA). For TEM measurement, a small amount of the sample was dispersed in chloroform and a drop of the dispersion was spread on a carbon-coated copper grid. The reduction of 4-NP and MB were measured using UV-vis spectrophotometry (Jenway 7315, Staffordshire, UK) at wavelengths of $400 \mathrm{~nm}$ and $665 \mathrm{~nm}$, respectively. The chemical composition and crystal structure of the samples were examined by X-ray diffraction (XRD, Bruker D8 Advance, Coventry, UK) under $\mathrm{Cu}$ $\mathrm{K} \alpha$ radiation. The current flow of the CuNWs was analyzed using Scanning Probe Microscope (SPM, NTEGRA NT-MDT, Moscow, Russia) and was operated by using the scanning spreading resistance microscopy (SSRM) mode. CuNWs were dispersed in chloroform and spin coated on a fluorine-doped tin oxide (FTO) glass slide for the SSRM measurements. 


\section{Results and Discussion}

\subsection{Characterization of $\mathrm{CuNWs}$}

The morphologies and sizes of the CuNWs were investigated by FESEM and TEM. Figure 1a,b shows the overview image of the synthesized CuNWs by FESEM and TEM, respectively. The aspect ratio of the CuNWs obtained was $\sim 2600$. The growth mechanism of CuNWs was due to the Ostwald ripening mechanism which was described by Sun et al. [37,38]. At the beginning, the formation of two distinctive sizes of CuNPs might simultaneously occur in the reaction solution. Surface energies of the larger particles are less than the smaller ones as the reaction proceeds, which causes the small CuNPs to spontaneously dissolve into the solution and recrystallize on the larger ones [38]. Anisotropic growth is possible with the presence of capping agent which enables control of the morphology of NWs; capping agents act as the structure-directing agent by complexing the $\mathrm{Cu}$ (II) ion [39]. Figure 1c shows the XRD diffractogram of the CuNWs synthesized by hydrothermal reaction. The results showed three diffraction peaks of (111), (200), and (220) at $2 \theta=43.2^{\circ}, 50.3^{\circ}$, and $74.2^{\circ}$, respectively. All diffraction peaks are those of face-centered cubic Cu (JCPDS04-0836) [40].

(a)

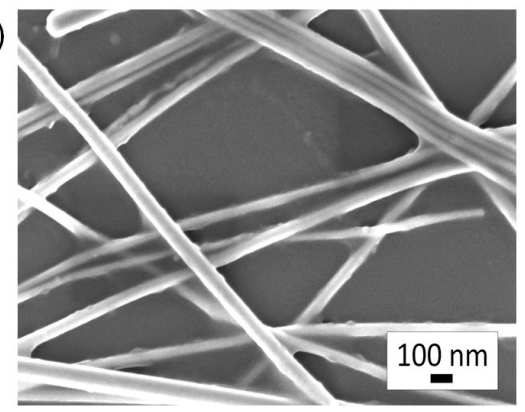

(b)

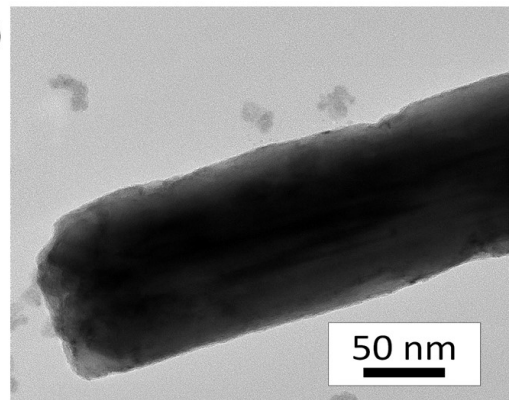

(C)

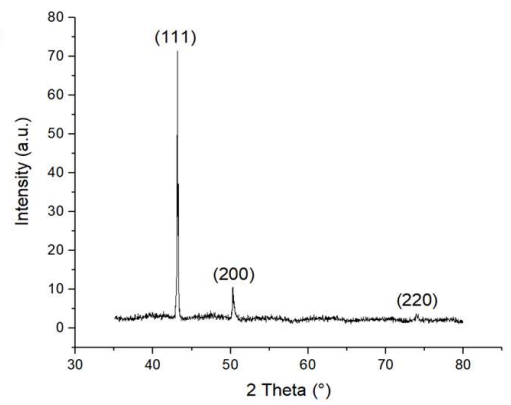

Figure 1. (a) FESEM image, (b) TEM image, and (c) XRD diffractogram of copper nanowires (CuNWs).

\subsection{Catalytic Reduction of 4-NP Using CuNWs}

\subsubsection{Effect of CuNWs Content}

To test the catalytic performance of the CuNWs, reduction of 4-NP to 4-AP was selected as the model reaction. The catalytic reaction does not occur when the CuNWs strips was not treated by GAA (Figure 2a). This might be due to the presence of a thin oxide layer and residual ODA presented on the surface of CuNWs [11] that prevent direct contact of reactants with the CuNWs. After CuNWs was treated with GAA for 10 mins, the reduction process occurred instantly. This shows that with GAA treatment, copper oxide, and residual capping agents can be removed from the surface of CuNWs without etching the underlying copper [2,41].

As can be seen from Figure $2 b$, the adsorption peak at $400 \mathrm{~nm}$ stayed almost unchanged in intensity for a long time which shows that the reduction of 4-nitrophenolate with only $\mathrm{NaBH}_{4}$ occurred very slowly. Amazingly, just by adding a minuscule amount of CuNWs ( $0.1 \mathrm{pg})$, the reduction process occurred instantaneously. As the peak of 4-nitrophenolate at $400 \mathrm{~nm}$ decreased, a new absorbance 
peak of 4-AP at $315 \mathrm{~nm} \mathrm{[20]} \mathrm{emerged} \mathrm{and} \mathrm{increased} \mathrm{with} \mathrm{time.} \mathrm{At} \mathrm{the} \mathrm{same} \mathrm{time,} \mathrm{the} \mathrm{yellow} \mathrm{color} \mathrm{of}$ 4-nitrophenolate changed to colorless, which also indicated the formation of 4-AP [42]. Figure 2c-e shows that by increasing the amount of CuNWs, the rate of catalytic reaction increases as well. Conversion of 4-NP to 4-AP up to $99 \%$ occurred in just 60,40 , and 25 sy using CuNWs loading of 0.1 , 0.5 , and $1 \mathrm{pg}$, respectively.

Figure $2 \mathrm{f}$ shows the plot of $\ln \left(\mathrm{C} / \mathrm{C}_{0}\right)$ against time for each of the CuNWs content tested. The concentration of $\mathrm{NaBH}_{4}$ can be considered as constant throughout the whole reaction due to its great excess in the reaction therefore, pseudo-first-order kinetics can be applied with respect to the concentration of 4-NP [17,43]. The rate constant for $0.1,0.5$, and $1 \mathrm{pg}$ are $0.076,0.11$, and $0.2 \mathrm{~s}^{-1}$, respectively. It can be seen that as the mass of catalyst increases, the rate constant value increases as well. This shows that the efficiency of the reduction of 4-NP increased in correlation to the catalyst loading. The increase in total surface area and the number of reaction sites can be the cause of this enhanced catalytic activity [44,45]. Table 1 shows the list of rate constant of previously reported $\mathrm{Cu}$-based catalysts for the reduction of 4-NP into 4-AP. The activity factor (K) was defined as the values of $k_{a p p}$ obtained from the slope over the total weight of catalyst [21,46]. Both the $k_{a p p}$ and $K$ obtained from this study by using $0.1 \mathrm{pg}$ CuNWs as catalyst shows a much higher value than the other form of $\mathrm{Cu}$ catalysts, indicating the excellent catalytic performance of CuNWs produced from this study.

In comparison to the catalytic reduction of 4-NP done by Sun et. al which also used CuNWs [21] as catalyst, both of the $k_{\text {app }}$ and $\mathrm{K}$ values are lower than the ones obtained in this study. The extremely high $\mathrm{k}_{\mathrm{app}}$ and $\mathrm{K}$ values could be related to the GAA treatment applied on CuNWs strip. The treatment applied could remove the oxide and residual capping layer, leaving the surface of CuNWs exposed to much easier and faster catalytic reactions. The capability of treatment using GAA was further proven by SSRM measurements by comparing the current signal of CuNWs before and after GAA treatment. Current flow of the CuNWs coated on FTO was increased from $3.45 \mathrm{nA}$ to $7.88 \mathrm{nA}$ after the GAA treatment.

Table 1. Studies on the reduction of 4-NP using various catalysts.

\begin{tabular}{cccc}
\hline Catalyst & $\mathbf{k}_{\text {app }}\left(\mathbf{s}^{\mathbf{- 1}}\right)$ & Activity Factor, $\mathbf{K}\left(\mathbf{s}^{\mathbf{- 1}} \mathbf{~ m g}^{\mathbf{- 1}}\right)$ & Reference \\
\hline CuNWs $(0.1 \mathrm{pg})$ & 0.076 & $7.6 \times 10^{8}$ & This study \\
Cu@MnO & 0.01142 & 0.571 & {$[12]$} \\
CuNPs $(12.5 \mathrm{mg})$ & 0.0016 & 0.00013 & {$[17]$} \\
CuNWs & 0.0042 & 0.046 & {$[21]$} \\
CuNW-Ag & 0.0067 & 0.074 & {$[21]$} \\
CuCubes $(9.5 \mathrm{~nm})$ & 0.0101 & 0.105 & {$[22]$} \\
CuNanoplate & 0.0095 & 0.136 & {$[46]$} \\
Porous Cu microsphere & 0.0043 & 0.072 & {$[47]$} \\
\hline
\end{tabular}

Electron transfer from the donor $\left(\mathrm{BH}_{4}{ }^{-}\right)$to acceptors (4-NP) can be accelerated by metal nanoparticles such as silver, gold and copper [14]. At room temperature, the liberation of hydrogen gas from $\mathrm{NaBH}_{4}$ by hydrolysis acts as a hydrogen source. The reaction can be catalytically enhanced by metals $[14,48]$. As stated before, without addition of catalyst, the reduction of 4NP occurred extremely slow and formation of 4-AP at absorbance peak $315 \mathrm{~nm}$ was not observed. The probable reaction steps for catalytic reduction of 4-NP to 4-AP are as follows:

Firstly, $\mathrm{NaBH}_{4}$ reduces water to hydrogen [49] which is as shown in Equation (3) below:

$$
\mathrm{NaBH}_{4}+\mathrm{H}_{2} \mathrm{O} \rightarrow \mathrm{NaBO}_{2}+4 \mathrm{H}_{2}
$$

The reduction process produces hydrogen gas which can be seen as bubbles in the solution. The isosbestic points can be found at 270 and $345 \mathrm{~nm}$, and indicate that the sole product of the reaction is 4-AP [50,51]. The reduction of 4NP can be explained by using the Langmuir-Hinshelwood model of heterogeneous catalyzed reduction [49,52]. Borohydride ions are adsorbed and reacted with the 
surface of CuNWs to produce active hydrogen species. At the same, 4-NP in the solution diffuses onto the surface of the nanowires and reacts with the active hydrogen species to form 4-AP. By lowering the activation energy of the reaction, CuNWs are able to catalytically contribute to the reduction of 4 -NP $[53,54]$.

(a)

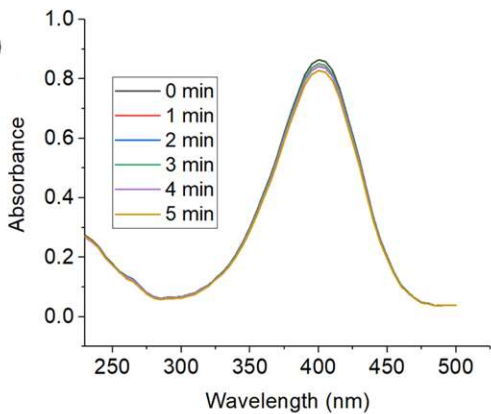

(c)

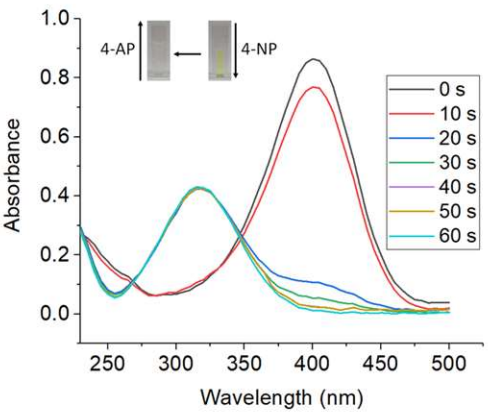

(e)

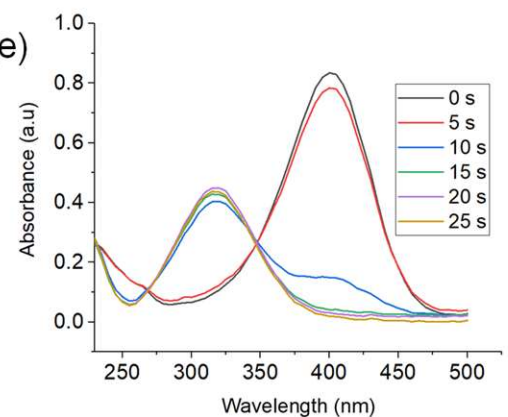

(b)

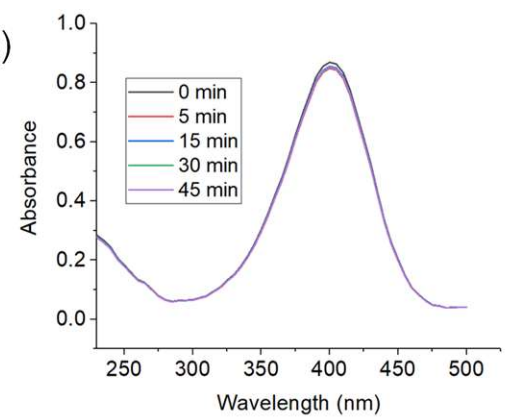

(d)

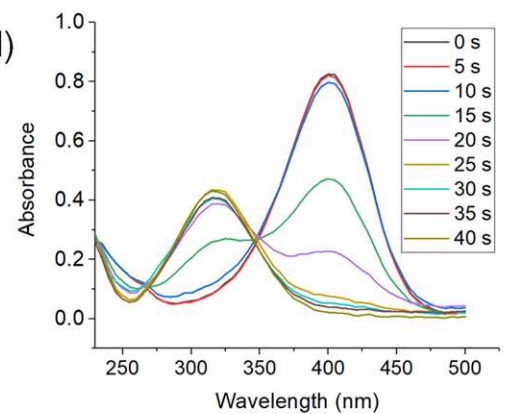

(f)

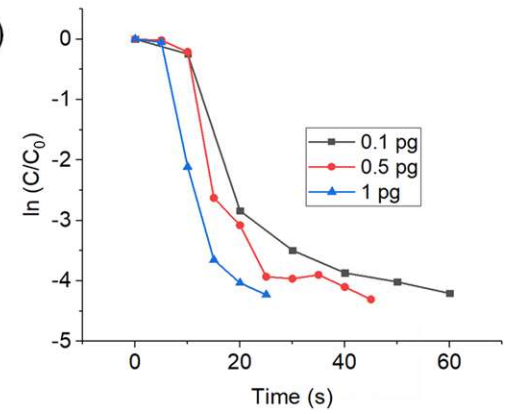

Figure 2. UV-vis spectra of 4-NP reduction reaction (a) no GAA treatment applied to CuNWs (b) no CuNWs added (c) $0.1 \mathrm{pg}$ CuNWs (d) $0.5 \mathrm{pg}$ CuNWs (e) $1 \mu \mathrm{g}$ CuNWs added as catalyst, and (f) plot of $\ln \left(C / C_{0}\right)$ against the reaction time for the reduction of 4-NP using different amount of CuNWs. (Reaction conditions: $5 \mathrm{~mL}$ of $[4-\mathrm{NP}]=1 \mathrm{mM}$ and $0.5 \mathrm{~mL}$ of $\left[\mathrm{NaBH}_{4}\right]=50 \mathrm{mM}$ ). The inset image in (c) is the color change of 4-NP to 4-AP.

\subsubsection{Effect of 4-NP and $\mathrm{NaBH}_{4}$ Concentration}

Figure 3a shows the plot of $\ln \left(\mathrm{C} / \mathrm{C}_{0}\right)$ against time for every concentration of $\mathrm{NaBH}_{4}$ tested. As the concentration of $\mathrm{NaBH}_{4}$ increases, the time taken for completion of reduction increases as well. The percentage of conversion also decreases with increase of $\mathrm{NaBH}_{4}$ used. For 25 and $50 \mathrm{mM}$ of $\mathrm{NaBH}_{4}$, the time taken for $99 \%$ reduction is 10 and $60 \mathrm{~s}$, respectively. Next, it takes $120 \mathrm{~s}$ for $75 \mathrm{mM}$ of $\mathrm{NaBH}_{4}$ used to reach reduction percentage of $98 \%$. Lastly, reduction percentage of $87 \%$ was reached in $300 \mathrm{~s}$ by using $100 \mathrm{mM} \mathrm{NaBH}_{4}$. The $\mathrm{k}_{\text {app }}$ also decreases with increasing concentrations of $\mathrm{NaBH}_{4}$ tested. The $\mathrm{k}_{\mathrm{app}}$ for $25,50,75$, and $100 \mathrm{mM}$ are $0.433,0.076,0.027$, and $0.0019 \mathrm{~s}^{-1}$, respectively. This is due to the inability of CuNWs to relay excess electrons $[55,56]$. 
(a)

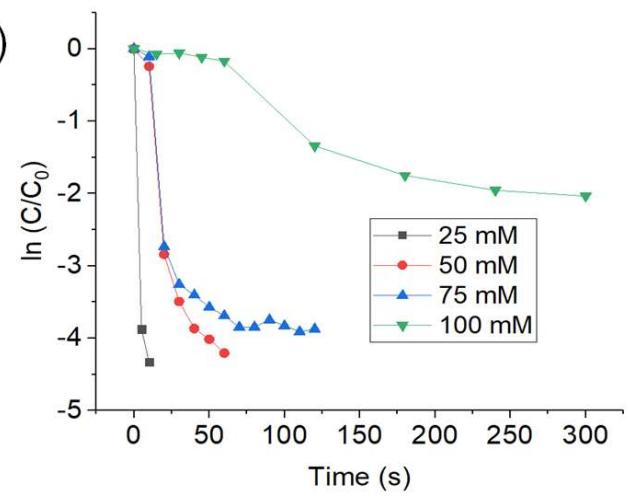

(b)

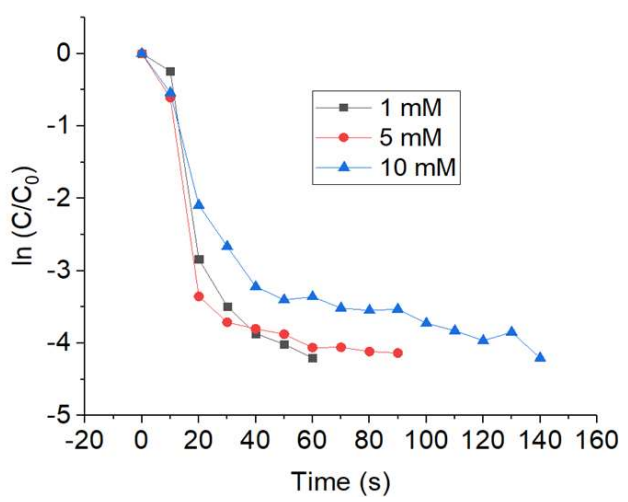

Figure 3. Plot of $\ln \left(\mathrm{C} / \mathrm{C}_{0}\right)$ against the reaction time for the reduction of 4-NP using (a) different concentrations of $\mathrm{NaBH}_{4}$, and (b) different concentrations of 4-NP. Mass of CuNWs used was $0.1 \mathrm{pg}$.

Next, Figure $3 \mathrm{~b}$ shows the plot of In $\left(\mathrm{C} / \mathrm{C}_{0}\right)$ against time for the concentrations of 4 -NP tested. The time taken for $99 \%$ reduction of $4-\mathrm{NP}$ is 60,90 , and $140 \mathrm{~s}$ for the concentrations of 4-NP 1, 5, and $10 \mathrm{mM}$, respectively. The $\mathrm{k}_{\mathrm{app}}$ for the concentrations of 1,5 , and $10 \mathrm{mM}$ are $0.076,0.041$, and $0.023 \mathrm{~s}^{-1}$, respectively. The decreasing trend in $\mathrm{k}_{\mathrm{app}}$ could be due to the competition between the two reactants (4-NP and $\mathrm{BH}_{4}^{-}$) to occupy the surface of CuNWs. Higher concentration of 4-NP has higher affinity to adsorb on the surface of CuNWs compared to $\mathrm{BH}_{4}{ }^{-}$ion and this lessen the occupancy sites of $\mathrm{BH}_{4}{ }^{-}$[57]. Liberation of hydrogen at the surface of $\mathrm{CuNWs}$ was limited due to the decreasing occupancy sites of $\mathrm{BH}_{4}^{-}$[58]. By using the Langmuir-Hinshelwood model, an efficient catalytic reduction through electron relay process is only achievable when both of the reactants are adsorbed onto the surface of catalyst in an almost equivalent amounts. Hence, the competition between 4-NP and $\mathrm{BH}_{4}{ }^{-}$would be less which resulted in a faster reaction with higher rate constant values. Lower reduction rate at higher concentrations of 4-NP is observed due to the poor electron delay between the reactants [57].

\subsubsection{Recyclability Test and Retreatment of CuNWs with GAA}

For the practical application of catalyst, stability and recyclability is very important. To test the recyclability of CuNWs as catalyst, the same CuNWs strip was used to reduce several batches of 4-NP. Based on Figure 4a, it can be seen that the first cycle of conversion process progressed smoothly but there is almost no reduction of 4-NP in the second cycle. Conversion percentage of 4-NP in the second cycle was only $1.6 \%$ in $120 \mathrm{~s}$ (Figure $4 \mathrm{~b}$ ). This is probably due to the by-products blocking the active sites of $\mathrm{CuNWs}$. Due to low conversion of the second cycle, retreatment of CuNWs using GAA was applied to see if there are any difference in the reduction progress. Figure $4 \mathrm{c}$ shows that the reduction of 4-NP can be continuously done by using the same CuNWs strip after retreatment with GAA before each cycle. This shows that the GAA treatment could remove all impurities from CuNWs surface which then enabled more catalytic reactions to occur.

Based on Figure $4 d$, the reduction process of the second cycle and above was faster ( 30 or $40 \mathrm{~s}$ ) compared to the first cycle $(60 \mathrm{~s})$. This shows that when the first round was initiated, the assumed adsorption equilibrium between CuNWs and 4-NP was not yet totally established [59]. The recyclability results demonstrated that the catalytic performance of $0.1 \mathrm{pg}$ CuNWs in a series of ten consecutive reduction reactions was stable and consistent without any significant difference. The reduction of 4-NP to 4-AP remained at $99 \%$ for the entire ten cycles. This shows that the small amount of CuNWs adhered extremely well to CC which resulted in good recoverability with high stability of catalytic activity. Videos S1 and S2 show that the catalytic reduction of 4-NP using CuNWs by using $0.1 \mathrm{pg}$ of CuNWs and $25 \mathrm{mM}$ of $\mathrm{NaBH}_{4}$. Video S1 shows that the rapid reduction of 4-NP using CuNWs as catalyst with a slight agitation by hand movement. Rapid continuous reduction of 4-NP can also be done as shown in Video S2. 
(a)

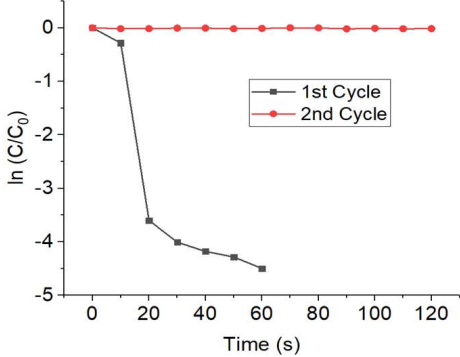

(c)

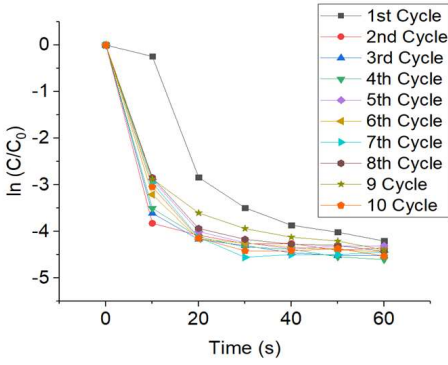

(b)

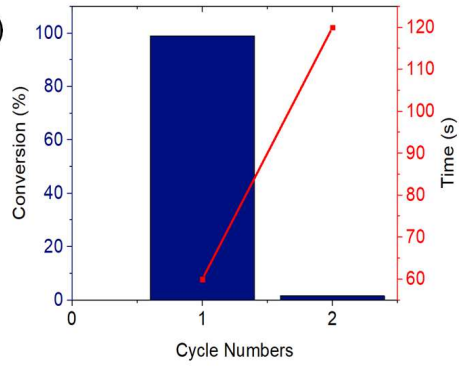

(d)

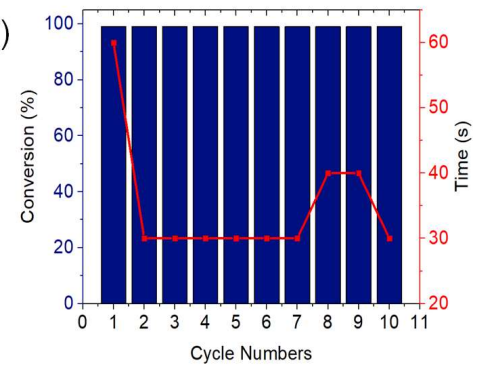

Figure 4. (a) Plot of $\ln \left(\mathrm{C} / \mathrm{C}_{0}\right)$ against the time for the reduction (b) conversion percentage of 4-NP and reaction time without retreatment of GAA, and (c) plot of $\ln \left(\mathrm{C} / \mathrm{C}_{0}\right)$ against the time for 10 cycles, and (d) conversion percentage of 4-NP and reaction time with retreatment of GAA.

\subsection{Clock Reaction of $M B$}

\subsubsection{Decolorization of $\mathrm{MB}$ using Sodium Borohydride $\left(\mathrm{NaBH}_{4}\right)$ as Reducing Agent}

To further test the catalytic activities of CuNWs, clock reaction of MB to LMB in the presence of $\mathrm{NaBH}_{4}$ was carried out. The blue color of solution is $\mathrm{MB}^{+}$which is the water soluble oxidized form of $\mathrm{MB}$ [24]. The reduction of MB can be observed at the maximum absorption wavelength of $665 \mathrm{~nm}$ [60]. When there is no catalyst added to the reaction, there is a very small reduction in maximum intensity value which shows that the reduction of $\mathrm{MB}$ with only $\mathrm{NaBH}_{4}$ is extremely slow. The reduction of $\mathrm{MB}$ is kinetically restricted without catalyst, even though it is thermodynamically favorable. This is caused by the large potential difference between donor and acceptor molecules [61].

Like silver, copper can transfer electrons between donor and acceptor species efficiently as it is a good electrical conductor. The catalytic process can be explained in terms of a redox mechanism where the transfer of electrons from donor $\mathrm{BH}_{4}{ }^{-}$ions to the acceptor (MB) is mediated by metal nanowires. This type of phenomenon where nanocrystal acts as redox catalyst is known as the "electron relay effect" [62]. Indication of reduction progress was evidenced by the color shift from blue to colorless. In this study, it was difficult to monitor the reduction of $\mathrm{MB}$ spectrophotometrically because of the promptness of color change in the presence of catalyst. Figure 5 a shows the UV-vis spectra of decolorization of MB to LMB. The reduction percentage of MB to LMB in $5 \mathrm{~s}$ by using $2 \mu \mathrm{g}$ CuNWs was $99 \%$.

The reduction reaction of MB to LMB is a two-electron process. The electron delocalization length of $\mathrm{MB}$ is reduced, and p-conjugation breaks due to the reduction of the double bond in the heterocyclic ring. Next, two electrons are transferred to $\mathrm{MB}^{+}$by $\mathrm{NaBH}_{4}$ [27]. By decreasing the concentration of dissolved oxygen in water, the amount of $\mathrm{NaBH}_{4}$ facilitates the formation of $\mathrm{LMB}$ [63]. To confirm the effect of catalyst on the oxidation of LMB to MB, CuNWs were removed immediately after the solution had turned colorless. The color changes back to blue which shows that the backward oxidation process could occur even after removal of catalyst. This verifies that the catalyst did not take part in the oxidation of LMB to MB [63].

The recolorization of MB by aerial oxidation doesn't fully oxidize LMB to MB. This is probably due to the small amount of oxygen presence in dry air which is only about 21\% [64]. Previously, Liu et al. reported that by the color of $\mathrm{MB}$ can return by using oxygen of 1 bar pressure [65], therefore in this study, $\mathrm{NaOH}$ is used instead of oxygen gas. After the complete conversion of $\mathrm{MB}$ to $\mathrm{LMB}, \mathrm{NaOH}$ was 
added into the solution. Figure $5 b$ shows the successive UV-vis spectra of different concentrations of $\mathrm{NaOH}$ added into LMB solution. Initially, $5 \mathrm{mg} / \mathrm{L}$ of MB has a maximum absorbance of 1.008 at $\lambda_{665}$. After that, CuNWs strip was inserted into MB solution and complete decolorization process can be observed by the bleaching of blue color. In absence of $\mathrm{NaOH}$, the highest absorbance value obtained after oxidation of LMB was 0.736 which shows that the MB color does not fully return.

It can be seen from Figure $5 b$ that when $\mathrm{NaOH}$ is added into the solution, the maximum absorbance value at $\lambda_{665}$ significantly increased. This shows that $\mathrm{NaOH}$ could help in the oxidation of LMB to MB. The absorbance value at $\lambda_{665}$ rose to 0.948 and 0.9967 when 0.01 and $0.1 \mathrm{M}$ of $\mathrm{NaOH}$ was added, respectively. Both are of higher absorbance value compared to the absence of $\mathrm{NaOH}$. This also shows that higher concentration of $\mathrm{NaOH}$ could effectively oxidize more LMB to MB. This is probably due to the hydroxyl ions from $\mathrm{NaOH}$. The hydroxyl ions would create an oxygen rich environment for LMB to convert back to MB. When higher concentration of $\mathrm{NaOH}$ is added, the amount of hydroxyl ions increased [66] which affects the oxidation of LMB. Furthermore, the recolorization rate increased when $\mathrm{NaOH}$ is added. In absence of $\mathrm{NaOH}$, it takes around $10 \mathrm{~min}$ for maximum conversion of LMB to $\mathrm{MB}$ in ambient condition. Just by adding $0.01 \mathrm{M} \mathrm{NaOH}$, the highest absorbance can be obtained in $30 \mathrm{~s}$ and this is similar when $0.1 \mathrm{M} \mathrm{NaOH}$ is added. This shows that $\mathrm{NaOH}$ also helps in speeding up the recolorization process of $\mathrm{MB}$. Figure $5 \mathrm{c}$ shows the schematic diagram of color switching between MB (blue) and LMB (colorless).
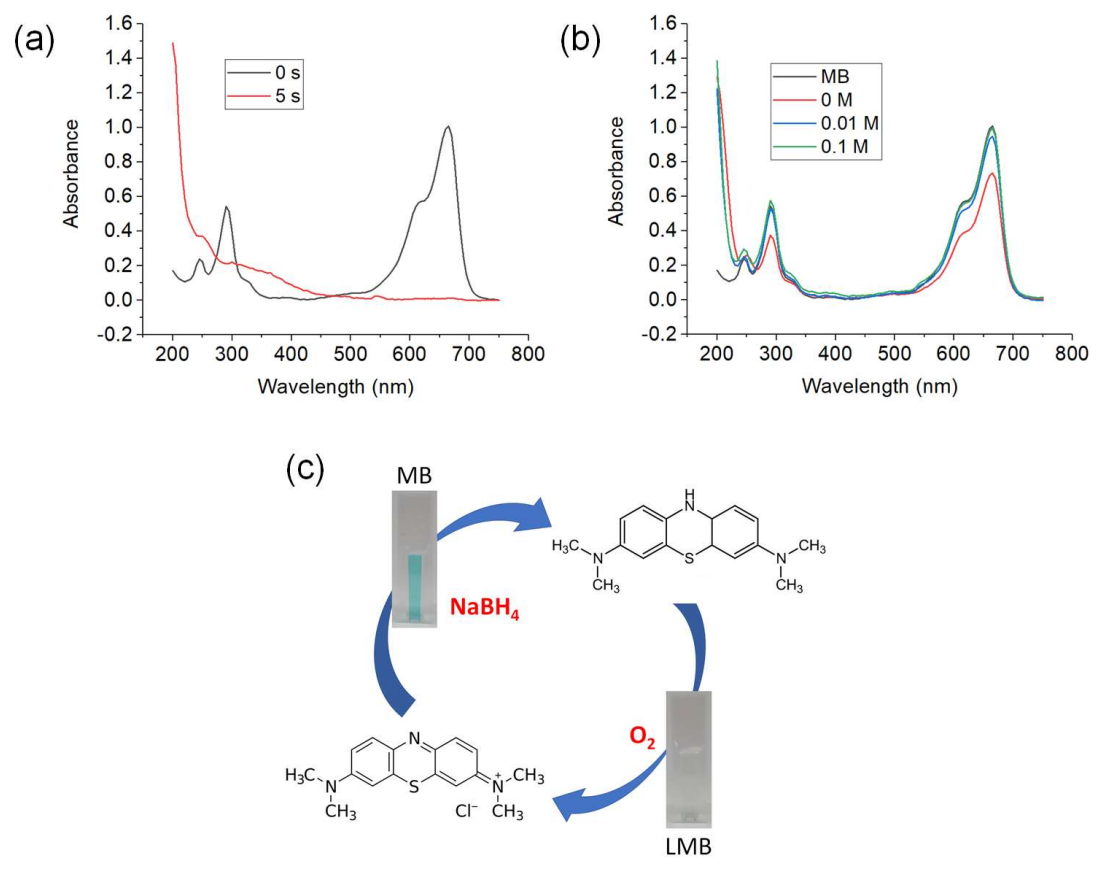

Figure 5. (a) UV-vis spectra of $\mathrm{MB}$ reduction reaction by $\mathrm{NaBH}_{4}$ using $2 \mu \mathrm{g}$ of CuNWs as catalyst, (b) successive UV-vis spectra of recolorization of LMB using $2 \mu \mathrm{g}$ of CuNWs by using different concentrations of $\mathrm{NaOH}$ (reaction conditions: $5 \mathrm{~mL}$ of $[\mathrm{MB}]=5 \mathrm{mg} / \mathrm{L}$ and $0.5 \mathrm{~mL}$ of $\left[\mathrm{NaBH}_{4}\right]=50 \mathrm{mM}$ ), and (c) the schematic diagram of clock reaction of $\mathrm{MB}$.

\subsubsection{Comparison of Decolorization of MB using Different Reducing Agents}

The catalytic performance of clock reaction of $\mathrm{MB}$ using CuNWs as catalyst was further studied by comparing different reducing agents of different strength to observe any difference in the clock reactions. The reducing agent tested were glucose and AA which are also greener and less toxic compared to $\mathrm{NaBH}_{4}$. Similarly, when $\mathrm{NaBH}_{4}$ is used as reducing agent, there is a very little decrease in the absorbance intensity value without the addition of catalyst. By using $2 \mu \mathrm{g}$ of $\mathrm{CuNWs}$ as comparison, both glucose and $\mathrm{AA}$ could not reduce $\mathrm{MB}$ and initiate the clock reaction in a short period of time as $\mathrm{NaBH}_{4}$. Reduction of MB by using glucose and AA progressed steadily through 30 min but the 
reduction is not as drastic and significant as when using $\mathrm{NaBH}_{4}$. The reason why glucose and $\mathrm{AA}$ could not initiate a swift reduction and clock reaction of $\mathrm{MB}$ like $\mathrm{NaBH}_{4}$ is probably due to the lower reducing strength. Table 2 shows the decolorization percentage of $\mathrm{MB}$ using glucose, $\mathrm{AA}, \mathrm{and}_{\mathrm{NaBH}}$.

Table 2. Comparison of the decolorization percentage of $\mathrm{MB}$ by using glucose, $\mathrm{AA}$, and $\mathrm{NaBH}_{4}$ as reducing agent.

\begin{tabular}{ccc}
\hline Reducing Agent & Time of Reaction (s) & Percentage of Decolorization of MB (\%) \\
\hline Glucose & 1800 & 35 \\
$\mathrm{AA}$ & 1800 & 43 \\
$\mathrm{NaBH}_{4}$ & 5 & 99 \\
\hline
\end{tabular}

\section{Conclusions}

In summary, CuNWs were synthesized using a simple hydrothermal method. They were used as catalyst for the reduction of 4-NP to 4-AP. The CuNWs exhibit superior catalytic activity: at just a minuscule amount of $0.1 \mathrm{pg}, 99 \%$ reduction of $4-\mathrm{NP}$ to $4-\mathrm{AP}$ occurred in only $60 \mathrm{~s}$. We also show how treatment of CuNWs using GAA helped in the reduction of 4-NP. CuNWs exhibit efficient and stable catalytic performance in up to ten consecutive cycles after retreatment with GAA. Furthermore, CuNWs showed rapid decolorization of MB to LMB in just $5 \mathrm{~s}$. We also studied how the addition of $\mathrm{NaOH}$ can be used to improve the oxidation of LMB to MB. Lastly, the reduction of MB in the presence of $\mathrm{CuNWs}$ as catalyst could not be achieved when using reducing agents of lower strength than $\mathrm{NaBH}_{4}$.

Supplementary Materials: The following are available online at http://www.mdpi.com/2079-4991/9/7/936/s1, Video S1: Reduction of 4-NP CuNWs, Video S2: Rapid continuous reduction of 4-NP by using CuNWs.

Author Contributions: Conceptualization, A.S.H., M.A.N.M.N. and C.H.C.; Methodology, A.S.H.; Software, A.S.H.; Validation, A.S.H., M.A.N.M.N. and C.H.C.; Formal analysis, A.S.H.; Writing-original draft preparation, A.S.H.; Writing-review and editing, A.S.H., S.X.C. and C.H.C.; Visualization, A.S.H. and M.A.N.M.N.; Supervision, C.H.C., S.X.C. and S.Z.; Project administration, C.H.C., S.X.C. and S.Z.; Funding acquisition, C.H.C., S.X.C. and S.Z.

Funding: This research was funded by NAME OF FUNDER, grant number GUP-2017-055 and the APC was funded by GGPM-2017-089.

Acknowledgments: The authors would like to thank the Centre of Research and Instrumentation (CRIM), UKM for the research grants (GUP-2017-055 \& GUP-2018-159) provided.

Conflicts of Interest: The authors declare no conflict of interest.

\section{References}

1. Zhang, X.; Chen, L.; Zheng, Y.; Tang, H.; Liu, Z. Determination of 4-nitrophenol in water using free-standing Cu nanowire electrode. Int. J. Electrochem. Sci. 2018, 13, 5698-5708. [CrossRef]

2. Wang, Y.; Liu, P.; Zeng, B.; Liu, L.; Yang, J. Facile synthesis of ultralong and thin copper nanowires and its application to high-performance flexible transparent conductive electrodes. Nano Res. Lett. 2018, 13, 78. [CrossRef] [PubMed]

3. Suchomel, P.; Kvitek, L.; Prucek, R.; Panacek, A.; Halder, A.; Vajda, S.; Zboril, R. Simple size-controlled synthesis of Au nanoparticles and their size-dependent catalytic activity. Sci. Rep. 2018, 8, 4589. [CrossRef]

4. Rahman, M.; Heng, L.Y.; Futra, D.; Chiang, C.P.; Rashid, Z.A.; Ling, T.L. A highly sensitive electrochemical DNA biosensor from acrylic-gold nano-composite for the determination of arowana fish gender. Nanoscale Res. Lett. 2017, 12, 484. [CrossRef] [PubMed]

5. Chook, S.W.; Chia, C.H.; Zakaria, S.; Neoh, H.M.; Jamal, R. Effective immobilization of silver nanoparticles on a regenerated cellulose-chitosan composite membrane and its antibacterial activity. New J. Chem. 2017, 41, 5061-5065. [CrossRef]

6. Abdul Halim, N.H.; Lee, Y.H.; Marugan, R.S.P.M.; Hashim, U. Mediatorless impedance studies with titanium dioxide conjugated gold nanoparticles for hydrogen peroxide detection. Biosensors 2017, 7, 38. [CrossRef] [PubMed] 
7. Chook, S.W.; Chia, C.H.; Kaco, H.; Zakaria, S.; Huang, N.M.; Neoh, H.M. Highly porous chitosan beads embedded with silver-graphene oxide nanocomposites for antibacterial application. Sains Malaysiana 2016, 45, 1663-1667.

8. Mock, J.; Bobinger, M.; Bogner, C.; Lugli, P.; Becherer, M. Aqueous synthesis, degradation, and encapsulation of copper nanowires for transparent electrodes. Nanomaterials 2018, 8, 767. [CrossRef]

9. Das, J.; Velusamy, P. Catalytic reduction of methylene blue using biogenic gold nanoparticles from Sesbania grandiflora L. J. Taiwan Inst. Chem. Eng. 2014, 45, 2280-2285. [CrossRef]

10. Ahmad, A.; Wei, Y.; Syed, F.; Imran, M.; Khan, Z.U.H.; Tahir, K.; Khan, A.U.; Raza, M.; Khan, Q.; Yuan, Q. Size dependent catalytic activities of green synthesized gold nanoparticles and electro-catalytic oxidation of catechol on gold nanoparticles modified electrode. RSC Adv. 2015, 5, 99364-99377. [CrossRef]

11. Mayousse, C.; Celle, C.; Carella, A.; Simonato, J.-P. Synthesis and purification of long copper nanowires. Application to high performance flexible transparent electrodes with and without PEDOT: PSS. Nano Res. 2014, 7, 315-324. [CrossRef]

12. Du, C.; He, S.; Gao, X.; Chen, W. Hierarchical $\mathrm{Cu} @ \mathrm{MnO}_{2}$ core-shell nanowires: A nonprecious-metal catalyst with an excellent catalytic activity toward the reduction of 4-nitrophenol. ChemCatChem 2016, 8, 2885-2889. [CrossRef]

13. Mohamed, M.M.; Al-Sharif, M.S. Visible light assisted reduction of 4-nitrophenol to 4-aminophenol on $\mathrm{Ag} / \mathrm{TiO}_{2}$ photocatalysts synthesized by hybrid templates. Appl. Catal. B Environ. 2013, 142, 432-441. [CrossRef]

14. Pandey, S.; Mishra, S.B. Catalytic reduction of p-nitrophenol by using platinum nanoparticles stabilised by guar gum. Carbohydr. Polym. 2014, 113, 525-531. [CrossRef]

15. Rodrigues, C.S.D.; Soares, O.S.G.P.; Pinho, M.T.; Pereira, M.F.R.; Madeira, L.M. p-Nitrophenol degradation by heterogeneous Fenton's oxidation over activated carbon-based catalysts. Appl. Catal. B Environ. 2017, 219, 109-122. [CrossRef]

16. Zhang, J.; Yan, Z.; Fu, L.; Zhang, Y.; Yang, H.; Ouyang, J.; Chen, D. Silver nanoparticles assembled on modified sepiolite nanofibers for enhanced catalytic reduction of 4-nitrophenol. Appl. Clay Sci. 2018, 166, 166-173. [CrossRef]

17. Deka, P.; Deka, R.C.; Bharali, P. In situ generated copper nanoparticle catalyzed reduction of 4-nitrophenol. New J. Chem. 2014, 38, 1789-1793. [CrossRef]

18. Tan, S.T.; Umar, A.A.; Salleh, M.M. (001)-Faceted hexagonal ZnO nanoplate thin film synthesis and the heterogeneous catalytic reduction of 4-nitrophenol characterization. J. Alloys Compd. 2015, 650, $299-304$. [CrossRef]

19. Li, B.; Hao, Y.; Zhang, B.; Shao, X.; Hu, L. A multifunctional noble-metal-free catalyst of $\mathrm{CuO} / \mathrm{TiO}_{2}$ hybrid nanofibers. Appl. Catal. A Gen. 2016, 531,1-12. [CrossRef]

20. He, R.; Wang, Y.C.; Wang, X.; Wang, Z.; Liu, G.; Zhou, W.; Wen, L.; Li, Q.; Wang, X.; Chen, X.; et al. Facile synthesis of pentacle gold-copper alloy nanocrystals and their plasmonic and catalytic properties. Nat. Commun. 2014, 5, 4327. [CrossRef]

21. Sun, Y.; Zhang, F.; Xu, L.; Yin, Z.; Song, X. Roughness-controlled copper nanowires and Cu nanowires-Ag heterostructures: Synthesis and their enhanced catalysis. J. Mater. Chem. A 2014, 2, 18583-18592. [CrossRef]

22. Zhang, P.; Sui, Y.; Xiao, G.; Wang, Y.; Wang, C.; Liu, B.; Zou, G.; Zou, B. Facile fabrication of faceted copper nanocrystals with high catalytic activity for p-nitrophenol reduction. J. Mater. Chem. A 2013, 1, 1632-1638. [CrossRef]

23. Lente, G.; Bazsa, G.; Fábián, I. What is and what isn't a clock reaction? New J. Chem. 2007, 31, 1707. [CrossRef]

24. Khan, A.A.; Kumar, M.; Khan, K.; Molla, A.; Hussain, S. Photoinduced oxygen prompted iron-iron oxide catalyzed clock reaction: Mimic of the blue bottle experiment. New J. Chem. 2017, 41, 6420-6426. [CrossRef]

25. Oliveira, A.P.; Faria, R.B. The chlorate-iodine clock reaction. J. Am. Chem. Soc. 2005, 127, 18022-18023. [CrossRef] [PubMed]

26. Neuenschwander, U.; Negron, A.; Jensen, K.F. A clock reaction based on molybdenum blue. J. Phys. Chem. A 2013, 117, 4343-4351. [CrossRef] [PubMed]

27. Ray, C.; Dutta, S.; Sarkar, S.; Sahoo, R.; Roy, A.; Pal, T. A facile synthesis of 1D nano structured selenium and Au decorated nano selenium: Catalysts for the clock reaction. RSC Adv. 2013, 3, 24313-24320. [CrossRef] 
28. Galagan, Y.; Su, W.F. Reversible photoreduction of methylene blue in acrylate media containing benzyl dimethyl ketal. J. Photochem. Photobiol. A Chem. 2008, 195, 378-383. [CrossRef]

29. Dilgin, Y.; Nişli, G. Fluorimetric determination of ascorbic acid in vitamin c tablets using methylene blue. Chem. Pharm. Bull. 2005, 53, 1251-1254. [CrossRef]

30. Wang, W.; Ye, Y.; Feng, J.; Chi, M.; Guo, J.; Yin, Y. Enhanced photoreversible color switching of redox dyes catalyzed by barium-doped $\mathrm{TiO}_{2}$ nanocrystals. Angew. Chemie Int. Ed. 2015, 54, 1321-1326. [CrossRef]

31. Lee, S.K.; Mills, A.; Lepre, A. An intelligence ink for oxygen. Chem. Commun. 2004, 1912-1913. [CrossRef] [PubMed]

32. Wang, W.; Ye, M.; He, L.; Yin, Y. Nanocrystalline $\mathrm{TiO}_{2}$-catalyzed photoreversible color switching. Nano Lett. 2014, 14, 1681-1686. [CrossRef] [PubMed]

33. Jiang, Y.; Zhang, S.; Ji, Q.; Zhang, J.; Zhang, Z.; Wang, Z. Ultrathin $\mathrm{Cu}_{7} \mathrm{~S}_{4}$ nanosheets constructed hierarchical hollow cubic cages: One-step synthesis based on Kirkendall effect and catalysis property. J. Mater. Chem. A 2014, 2, 4574-4579. [CrossRef]

34. Pal, J.; Ganguly, M.; Dutta, S.; Mondal, C.; Negishi, Y.; Pal, T. Hierarchical Au-CuO nanocomposite from redox transformation reaction for surface enhanced Raman scattering and clock reaction. CrystEngComm 2014, 16, 883-893. [CrossRef]

35. Ahmadi, R.; Jafarzadeh, M.; Khodaei, M.M.; Adnan, R. Encapsulation of Ag nanoparticles in magnetically modified silica nanostructures for reduction of 4-nitrophenol. Monatshefte fur Chemie 2017, 148, 1423-1431. [CrossRef]

36. Qian, F.; Lan, P.C.; Olson, T.; Zhu, C.; Duoss, E.B.; Spadaccini, C.M.; Han, T.Y.-J. Multiphase separation of copper nanowires. Chem. Commun. 2016, 52, 11627-11630. [CrossRef] [PubMed]

37. Sun, Y.; Gates, B.; Mayers, B.; Xia, Y. Crystalline silver nanowires by soft solution processing. Nano Lett. 2002, 2, 165-168. [CrossRef]

38. Ruan, H.; Wang, R.; Luo, Y.; Liu, H.; Han, T.; Yang, L. Study on synthesis and growth mechanism of copper nanowires via a facile oleylamine-mediated process. J. Mater. Sci. Mater. Electron. 2016, 27, 9405-9409. [CrossRef]

39. Tan, M.; Balela, M.D. One-pot synthesis of high aspect ratio copper nanowires in aqueous solution. Adv. Mater. Res. 2015, 1119, 34-37. [CrossRef]

40. Wang, R.; Ruan, H. Synthesis of copper nanowires and its application to flexible transparent electrode. J. Alloys Compd. 2016, 656, 936-943. [CrossRef]

41. Chavez, K.L.; Hess, D.W. A novel method of etching copper oxide using acetic acid. J. Electrochem. Soc. 2001, 148, G640-G643. [CrossRef]

42. Chen, Y.; Zhang, Y.; Kou, Q.; Liu, Y.; Han, D.; Wang, D.; Sun, Y.; Zhang, Y.; Wang, Y.; Lu, Z.; et al. Enhanced catalytic reduction of 4-nitrophenol driven by Fe3O4-Au magnetic nanocomposite interface engineering: From facile preparation to recyclable application. Nanomaterials 2018, 8, 353. [CrossRef] [PubMed]

43. Saha, S.; Pal, A.; Kundu, S.; Basu, S.; Pal, T. Photochemical green synthesis of calcium-alginate-stabilized $\mathrm{Ag}$ and Au nanoparticles and their catalytic application to 4-nitrophenol reduction. Langmuir 2009, 26, 2885-2893. [CrossRef] [PubMed]

44. Li, Y.; Lan, J.Y.; Liu, J.; Yu, J.; Luo, Z.; Wang, W.; Sun, L. Synthesis of gold nanoparticles on rice husk silica for catalysis applications. Ind. Eng. Chem. Res. 2015, 54, 5656-5663. [CrossRef]

45. Zhao, S.; Duan, L.; Xiao, C.; Li, L.; Liao, F. Single metal of silver nanoparticles in the microemulsion for recyclable catalysis of 4-nitrophenol reduction. J. Adv. Nanomater. 2017, 2, 31-40. [CrossRef]

46. Sun, Y.; Xu, L.; Yin, Z.; Song, X. Synthesis of copper submicro/nanoplates with high stability and their recyclable superior catalytic activity towards 4-nitrophenol reduction. J. Mater. Chem. A 2013, 1, 12361-12370. [CrossRef]

47. Gao, S.; Jia, X.; Yang, J.; Wei, X. Hierarchically micro/nanostructured porous metallic copper: Convenient growth and superhydrophilic and catalytic performance. J. Mater. Chem. 2012, 22, 21733-21739. [CrossRef]

48. Rakap, M.; Özkar, S. Hydroxyapatite-supported cobalt(0) nanoclusters as efficient and cost-effective catalyst for hydrogen generation from the hydrolysis of both sodium borohydride and ammonia-borane. Catal. Today 2012, 183, 17-25. [CrossRef] 
49. Seoudi, R.; Al-Marhaby, F.A. Synthesis, characterization and photocatalytic application of different sizes of gold nanoparticles on 4-nitrophenol. World J. Nano Sci. Eng. 2016, 6, 120. [CrossRef]

50. Deka, P.; Sarmah, P.; Deka, R.C.; Bharali, P. Hetero-nanostructured Ni $/ \alpha-\mathrm{Mn}_{2} \mathrm{O}_{3}$ as highly active catalyst for aqueous phase reduction reactions. ChemistrySelect 2016, 1, 4726-4735. [CrossRef]

51. Guerrero-Araque, D.; Acevedo-Peña, P.; Ramírez-Ortega, D.; Gómez, R. Improving photocatalytic reduction of 4-nitrophenol over $\mathrm{ZrO}_{2}-\mathrm{TiO}_{2}$ by synergistic interaction between methanol and sulfite ions. New J. Chem. 2017, 41, 12655-12663. [CrossRef]

52. Khalavka, Y.; Becker, J.; Sönnichsen, C. Synthesis of rod-shaped gold nanorattles with improved plasmon sensitivity and catalytic activity. J. Am. Chem. Soc. 2009, 131, 1871-1875. [CrossRef] [PubMed]

53. Antonels, N.C.; Meijboom, R. Preparation of well-defined dendrimer encapsulated ruthenium nanoparticles and their evaluation in the reduction of 4-nitrophenol according to the Langmuir-Hinshelwood approach. Langmuir 2013, 29, 13433-13442. [CrossRef] [PubMed]

54. Alegria, E.; Ribeiro, A.; Mendes, M.; Ferraria, A.; do Rego, A.; Pombeiro, A. Effect of phenolic compounds on the synthesis of gold nanoparticles and its catalytic activity in the reduction of nitro compounds. Nanomaterials 2018, 8, 320. [CrossRef] [PubMed]

55. Ranchani, A.A.J.; Parthasarathy, V.; Devi, A.A.; Meenarathi, B.; Anbarasan, R. Synthesis, characterization and catalytic activity of nanosized Ni complexed aminoclay. Appl. Nanosci. 2017, 7, 577-588. [CrossRef]

56. Akhondi, M.; Jamalizadeh, E. Fabrication of silver-modified halloysite nanotubes and their catalytic performance in rhodamine 6G and methyl orange reduction. Acta Chim. Slov. 2019, 66, 136-144. [CrossRef]

57. Priya, D.B.; Asharani, I.V. Catalytic reduction in 4-nitrophenol using Actinodaphne madraspatana Bedd leaves-mediated palladium nanoparticles. IET Nanobiotechnol. 2017, 12, 116-126. [CrossRef]

58. Kalekar, A.M.; Sharma, K.K.K.; Luwang, M.N.; Sharma, G.K. Catalytic activity of bare and porous palladium nanostructures in the reduction of 4-nitrophenol. RSC Adv. 2016, 6, 11911-11920. [CrossRef]

59. Vilar-Vidal, N.; Rivas, J.; Lopez-Quintela, M. Size dependent catalytic activity of reusable subnanometer copper(0) clusters. ACS Catal. 2012, 2, 1693-1697. [CrossRef]

60. Basu, M.; Sinha, A.K.; Pradhan, M.; Sarkar, S.; Pal, A.; Mondal, C.; Pal, T. Methylene blue-Cu $2 \mathrm{O}$ reaction made easy in acidic medium. J. Phys. Chem. C 2012, 116, 25741-25747. [CrossRef]

61. Du, S.; Liao, Z.; Qin, Z.; Zuo, F.; Li, X. Polydopamine microparticles as redox mediators for catalytic reduction of methylene blue and rhodamine B. Catal. Commun. 2015, 72, 86-90. [CrossRef]

62. Saad, A.; Snoussi, Y.; Abderrabba, M.; Chehimi, M.M. Ligand-modified mesoporous silica SBA-15/silver hybrids for the catalyzed reduction of methylene blue. RSC Adv. 2016, 6, 57672-57682. [CrossRef]

63. Das, B.; Sharma, M.; Sarmah, J.C.; Bania, K.K. Rapid reduction of dye pollutants and hexavalent chromium by silver-sulphur oxido-vanadium cluster. J. Environ. Chem. Eng. 2017, 5, 4212-4219. [CrossRef]

64. Peacock, A.J. Oxygen at high altitude. Bmj 1998, 317, 1063-1066. [CrossRef] [PubMed]

65. Liu, Y.N.; Zhou, X.; Wang, X.; Liang, K.; Yang, Z.K.; Shen, C.C.; Imran, M.; Sahar, S.; Xu, A.W. Hydrogenation/oxidation induced efficient reversible color switching between methylene blue and leuco-methylene blue. RSC Adv. 2017, 7, 30080-30085. [CrossRef]

66. Yang, D.; Guo, G.; Hu, J.; Wang, C.; Jiang, D. Hydrothermal treatment to prepare hydroxyl group modified multi-walled carbon nanotubes. J. Mater. Chem. 2008, 18, 350-354. [CrossRef]

(C) 2019 by the authors. Licensee MDPI, Basel, Switzerland. This article is an open access article distributed under the terms and conditions of the Creative Commons Attribution (CC BY) license (http://creativecommons.org/licenses/by/4.0/). 